\title{
IMPOSTO SOBRE SERVIÇOS E PLANOS OU CONVÊNIOS FUNERÁRIOS: ANÁLISE CRÍTICA DO SUBITEM 25.03 DA LISTA ANEXA À LEI COMPLEMENTAR No. 116/03
}

\author{
TAX ON SERVICES AND FUNERAL INSURANCE PLANS: CRITICAL ANALYSIS OF THE \\ SUB-ITEM 25.03 OF THE LIST ATTACHED TO COMPLEMENTARY LAW N. 116/03
}

\section{Martha Toribio Leão*}

Sumário: Introdução. 1. O critério material da hipótese de incidência do ISS. 2. O papel da lei complementar $n^{\circ}$. 116/03. 3. A inexistência de serviço tributável na simples contratação de plano ou convênio funerário. 4. Análise crítica da jurisprudência do Tribunal de Justiça de São Paulo e do Superior Tribunal de Justiça. Considerações finais. Referências.

Resumo: O artigo aborda o tema da incidência do Imposto sobre Serviços - ISS sobre a venda de planos ou convênios funerários, enquanto contratos atípicos pelos quais uma pessoa contrata e paga, em vida, pelos serviços funerários que devem ser prestados quando do seu falecimento. Para isso, parte da análise do critério material da hipótese de incidência do ISS, bem como do papel da lei complementar dentro da estrutura desse imposto. Depois disso, examina de forma concreta a situação dos planos e convênios funerários a fim de demonstrar porque esse negócio jurídico não se enquadra no fato gerador do ISS.

Palavras-chave: Imposto sobre Serviços; Planos e Convênios Funerários; Serviço; Lei complementar.

\footnotetext{
* Universidade de São Paulo.
} 
Abstract: The article approaches the issue of the Tax on Services (ISS) on the sale of funeral insurance plans, as atypical contracts by which a person hires and pays in life, the funeral services to be provided at the time of his death. For this, it starts from the analysis of the substantial criterion of the incidence hypothesis of the ISS, as well as of the role of complementary law within the framework of this tax. After this, it concretely examines the situation of funeral insurance plans in order to demonstrate why this legal business does not fits in the taxable event of the ISS.

Keywords: Tax Services; Funeral Plans and Agreements; Service; Complementary Law.

\section{INTRODUÇÃO}

A diversidade dos negócios jurídicos sempre traz a necessidade de evolução e adaptação do Direito. É exatamente nessa linha que se insere a questão dos planos ou convênios funerários, enquanto contrato em que uma pessoa em vida paga pelos serviços funerários ou de cremação para o seu próprio falecimento. Trata-se de negócio atípico, envolvendo a provável prestação futura, em data incerta, de serviços funerários e de cremação. Atento a essa recente modalidade negocial, o legislador complementar de 2003 incluiu um subitem específico sobre o tema na Lista Anexa à Lei Complementar nº 116/03.

Ao fazê-lo, porém, parece ter indicado a possibilidade de que o Imposto sobre a Prestação de Serviços - ISS incidisse tão logo fosse concretizada a contratação desse tipo de plano ou convênio funerário. O presente artigo, portanto, tem a intenção de analisar criticamente esse subitem, para ao fim demonstrar a impossibilidade de que a mera contratação de um serviço em potencial ou de uma utilidade seja considerada situação tributável para fins de ISS, à luz das regras de competência discriminadas na Constituição e no próprio Código Tributário Nacional.

Para isso, iniciaremos com a análise do critério material da hipótese de incidência do ISS e da própria função da lei complementar dentro da estrutura desse imposto. A partir daí, partiremos para a apreciação concreta do subitem 25.03 da Lista Anexa à Lei Complementar $\mathrm{n}^{\mathrm{o}}$. 116/03, analisando porque os planos ou convênios funerários não se consubstanciam em situação fática necessária e suficiente para a ocorrência do fato gerador do ISS. Além disso, ao final, ainda traremos alguns julgados sobre o tema, que servem como indicativo dos 
problemas que serão enfrentados na medida em que essas situações alcancem o Poder Judiciário.

\section{O CRITÉRIO MATERIAL DA HIPÓTESE DE INCIDÊNCIA DO ISS}

Em um sistema constitucionalizado como o sistema tributário brasileiro, qualquer análise acerca da possibilidade de instituição (ou não) de determinado tributo perante uma situação fática deve necessariamente partir da Constituição. Isso porque, foi a própria Constituição quem delimitou de forma minuciosa a discriminação das competências entre os entes federados, tendo ainda, muitas vezes, definido a própria materialidade do fato gerador.

Para o deslinde do tema ora proposto, portanto, partiremos do texto constitucional, até mesmo porque o Imposto sobre Serviços - ISS é um desses tributos sobre os quais o constituinte já pré-definiu, na outorga de competência, a delimitação do fato gerador. Nesse sentido, o artigo 156, inciso IV prevê que compete aos Municípios instituir impostos sobre serviços de qualquer natureza, não compreendidos no artigo 155, inciso I, alínea $b$ (norma de competência referente ao ICMS) e definidos em lei complementar. ${ }^{1}$ Resta claro, dessa forma, que a autorização constitucional para a tributação pelo ISS está limitada à existência de um serviço.

Resta, então, definir qual o conceito de serviço para fins de delimitação do critério material da hipótese de incidência. No ponto, importante elucidarmos que nos filiamos à corrente que acredita que a Constituição, ao delimitar os campos de competência de cada um dos entes federados, trabalhou com conceitos e não com tipos. ${ }^{2}$ Entendemos, apesar de ilustres posicionamentos em contrário $^{3}$, que o legislador constituinte discriminou a competência impositiva mediante referência a conceitos determinados. Com efeito, como já explicitado por PAULO AYRES, afirmar que é o legislador infraconstitucional quem vai definir as referências sígnicas constitucionais implicaria esvaziar, por completo, o esforço do

\footnotetext{
${ }^{1}$ Art. 156. Compete aos Municípios instituir impostos sobre:

(...) IV serviços de qualquer natureza, não compreendidos no art. 155, I, b, definidos em lei complementar.

2 Sobre o tema, vide, por todos: SCHOUERI, Luís Eduardo. Normas Tributárias Indutoras e Intervenção Econômica. Rio de Janeiro: Forense, 2005; DERZI, Misabel de Abreu Machado. Direito Tributário, Direito Penal e Tipo. São Paulo, Revista dos Tribunais, 1988.

${ }^{3}$ Nesse sentido, LUÍS EDUARDO SCHOUERI é firme ao defender que o constituinte utilizou-se de tipos e não conceitos ao delimitar as esferas de competência, afirmando que os signos utilizados seriam "meros nomes dados historicamente a impostos já existentes. Por isso, afirmamos que o constituinte não conceituou os impostos pertencentes a cada esfera tributante, apenas nominou-os contemplando um todo. Valendo-nos das lições da teoria geral do direito, concluímos que o constituinte apenas contemplou a realidade a partir de tipos" (SCHOUERI, Luís Eduardo. Discriminação de Competências e Competência Residual. In: SCHOUERI, Luís Eduardo; ZILVETI, Fernando Aurélio (Orgs.). Direito Tributário: Estudos em Homenagem a Brandão Machado. São Paulo, 1998, p. 115).
} 
Constituinte de 1988 na repartição das competências impositivas. Seria o mesmo que dizer que ele teria elaborado uma discriminação de competências, para nada discriminar. ${ }^{4}$ Estabelecida essa premissa, podemos nos ater a definir qual é o conceito constitucional de serviço.

Ao utilizar o termo "serviços" na regra de competência tributária municipal, sem conceituá-lo de forma diversa, a Constituição incorporou o conceito infraconstitucional préconstitucional de obrigação de fazer, cujo núcleo semântico é o esforço humano compreendido em benefício de outrem. ${ }^{5}$ O próprio Tribunal Pleno do Supremo Tribunal Federal já se manifestou sobre o tema, ao analisar a instituição do ISS relativamente aos contratos de locação, tendo decidido que o conceito de serviço seria aquele previsto no direito infraconstitucional pré-constitucional, qual seja, o conceito de obrigação de fazer previsto no Código Civil. ${ }^{6}$

Considerando esse ponto de partida e seguindo as lições de PAULO DE BARROS CARVALHO, de que o critério material é o núcleo da hipótese de incidência e é formado, invariavelmente, por um verbo e seu complemento ${ }^{7}$, no caso do ISS, o critério material não pode ser outro senão a expressão "prestar serviço". Para configurá-lo, é necessário que ocorra o exercício, por parte de alguém (no caso, o prestador), de atuação que tenha por objetivo produzir uma utilidade relativamente a outra pessoa (no caso, o tomador), a qual remunera o prestador (preço do serviço).

Em outras palavras, trata-se de uma atividade irreflexiva, que reivindica um caráter bilateral e oneroso. ${ }^{8}$ AIRES BARRETO, na mesma direção, é firme em afirmar que a essência da hipótese de incidência do ISS não está no termo "serviço" isoladamente considerado, mas na atividade humana que dele decorre, vale dizer, na prestação de serviço. O aspecto material da hipótese de incidência é a conduta humana (prestação de serviço) consistente em desenvolver um esforço visando a adimplir uma obrigação de fazer. ${ }^{9}$

\footnotetext{
${ }^{4}$ BARRETO, Paulo Ayres. Elisão Tributária: Limites Normativos. São Paulo, USP, 2008, p. 73.

${ }^{5}$ Nesse sentido: AVILA, Humberto. "Imposto sobre a Prestação de Serviços de Qualquer Natureza. ISS. Normas constitucionais aplicáveis. Precedentes do Supremo Tribunal Federal. Hipótese de incidência, base de cálculo e local da prestação. Leasing financeiro: análise da incidência. Revista Dialética de Direito Tributário, v. 182, São Paulo, nov./2010, pp. 133-144.

${ }^{6}$ Recurso Extraordinário $\mathrm{n}^{\mathbf{0}}$ 116.121-3, STF, Tribunal Pleno, Relator: Ministro Octávio Gallotti, Relator para acórdão: Ministro Marco Aurélio, julgado em 11.10.00, DJ 25.05.01, p. 17.

${ }^{7}$ CARVAlHO, Paulo de Barros. Curso de Direito Tributário. 23. ed. São Paulo: Saraiva, 2011, p. 325. Sobre o tema, vide também: ATALIBA, Geraldo. Hipótese de Incidência Tributária. São Paulo: Revista dos Tribunais, 1973, p. 111; SCHOUERI, Luís Eduardo. Direito Tributário. São Paulo: Saraiva, 2011, p. 446.

${ }^{8}$ CARVAlHO, Paulo de Barros. Direito Tributário, Linguagem e Método. 3. ed. São Paulo: Noeses, 2009, pp. 767-768.

${ }^{9}$ BARRETO, Aires F. Curso de Direito Tributário Municipal. São Paulo: Saraiva, 2009, pp. 319-320.
} 
Nesse sentido, a prestação de serviço deve envolver necessariamente uma obrigação de fazer e não de dar. Essa constatação decorre não apenas da natureza do termo serviço, como também da própria análise conjunta da discriminação de competências prevista na Constituição. O postulado da unidade do ordenamento jurídico implica a necessária relação entre parte e conjunto, de tal sorte que a interpretação da norma pressupõe a do sistema do qual ela faz parte e vice-versa. ${ }^{10}$

Para HUMBERTO ÁVILA, o conjunto de normas pertencentes ao direito tributário será formado pela compreensão sistemática dos dispositivos que expressa ou implicitamente, imediata ou mediatamente, entrem em contato com os bens jurídicos restringidos na concretização da relação obrigacional tributária. Sendo assim, a delimitação dos contornos do critério material também pode ser extraída da Constituição por meio da sua distinção relativamente a outras hipóteses de incidência que a própria Carta Magna estabelece, isto é, por meio de delimitação negativa das regras de competência. ${ }^{11}$

A Constituição atribuiu aos Estados e Municípios competência para tributar diferentes situações demonstrativas de capacidade econômica. Aos primeiros, permitiu a instituição de impostos sobre "operações relativas à circulação de mercadorias" (art. 155, inciso II, da Constituição). Aos segundos, atribuiu o poder de tributar os "serviços de qualquer natureza, não compreendidos no art. 155, inciso II, definidos em lei complementar" (art. 156, inciso III, da Constituição). Sobre o ponto, PAULO AYRES e EURICO DE SANTI, em parecer exarado em conjunto, afirmam que a conotação do termo utilizado na definição constitucional das competências tributárias (renda, prestação de serviços, importação, exportação, etc) é que irá demarcar os lindes laterais da atuação legislativa dos entes tributantes. ${ }^{12}$

Na mesma linha, ROBERTO QUIROGA MOSQUERA é firme ao apontar que a repartição de competências na Carta Magna elencou situações de vida distintas e que estes fatos representam realidades diferentes, apresentando características particulares e específicas. Logo, os conceitos diferentes utilizados pelo constituinte não podem ser misturados, indicando uma diferenciação que precisa ser respeitada. ${ }^{13} \mathrm{Em}$ outras palavras, as situações

\footnotetext{
${ }^{10}$ ALEXY, Robert. Juristiche Interpretation. In: Recht, Vernunft, Diskurs. Frankfurt am Main: Suhrkamp, 1995, p. 75.

11 ÁVILA, Humberto. Conceito de renda e compensação de prejuízos fiscais. São Paulo: Malheiros, pp. 14; 33.

12 SANTI, Eurico Marcos Diniz de; BARRETO, Paulo Ayres. Contribuições para Previdência Privada Dedutibilidade em face do Imposto sobre a Renda - Força da EC 20/98 - Aplicabilidade da Lei 9.532/97 no Tempo. Revista Dialética de Direito Tributário, vol. 93, junho/03, p. 125.

${ }^{13}$ MOSQUERA, Roberto Quiroga. Os Impostos sobre Operações de Crédito, Câmbio, Seguro ou Relativos a Títulos ou Valores Mobiliários - Conceitos Fundamentais. In: SANTI, Eurico Marcos Diniz de; ZILVETI, Fernando Aurélio; MOSQUERA, Roberto Quiroga (Orgs.). Tributação Internacional e dos Mercados
} 
fáticas passíveis de tributação já foram desenhadas e separadas pelo constituinte, cabendo ao legislador infraconstitucional se submeter a elas, sob pena de incorrer em inconstitucionalidade.

Diante disso, está claro que as regras constitucionais delimitaram as competências tributárias do seguinte modo: o imposto sobre serviços incide sobre o esforço humano, isto é, sobre as obrigações de fazer (exceto sobre as prestações de serviços de transporte interestadual e intermunicipal e de comunicação) e o imposto sobre circulação de mercadorias incide sobre a transferência de bens, ou seja, sobre as obrigações de dar.

Não há dúvida, portanto, acerca da obrigatoriedade de que a atividade realizada pelo prestador apresente-se sob a forma de obrigação de fazer, só sendo possível a incidência de ISS se houver negócio jurídico mediante o qual uma das partes se obrigue a praticar certa atividade, de natureza física ou intelectual, recebendo, em troca, remuneração. ${ }^{14}$ Nessa linha, o artigo $1^{\circ}$ da Lei Complementar $n^{o}$. 116/03 nada mais fez do que explicitar o que já estava definido pela Constituição, ao afirmar que o fato gerador do ISS é a prestação de serviços, já em seu artigo $1^{\circ}$ : o Imposto Sobre Serviços de Qualquer Natureza, de competência dos Municípios e do Distrito Federal, tem como fato gerador a prestação de serviços constantes da lista anexa, ainda que esses não se constituam como atividade preponderante do prestador.

Em resumo, são intransponíveis os limites conceituais previstos nas regras de competência. Fora deles, não há poder de tributar. ${ }^{15}$ A esse respeito, já decidiu o próprio Supremo Tribunal Federal, ao asseverar que o intérprete “... não deve ir além dos limites semânticos, que são intransponíveis". ${ }^{16}$

\section{O PAPEL DA LEI COMPLEMENTAR Nº $116 / 03$}

Financeiro e de Capitais. São Paulo: Quartier Latin, 2005, pp. 103-104. Também nesse sentido: Renda $e$ proventos de qualquer natureza - o imposto e o conceito constitucional. São Paulo: Dialética, 1996, p. 81.

${ }^{14}$ CARVAlHO, Paulo de Barros. Direito Tributário, Linguagem e Método. 3. ed. São Paulo: Noeses, 2009 , p. 768.

15 Também nesse sentido: TORRES, Heleno. A Hipótese do ICMS sobre Operações Mercantis na Constituição e a Solução de Conflitos Normativos. In: SCHOUERI, Luís Eduardo (Org.). Direito Tributário - Homenagem a Paulo de Barros Carvalho. São Paulo: Quartier Latin, 2008, pp. 321-342.

${ }^{16}$ Recurso Extraordinário no 71.758, Relator Ministro Thompson Flores, RTJ 66, p. 150. 
A Constituição expressamente conferiu à lei complementar a competência para definir quais seriam os serviços de qualquer natureza compreendidos dentro da competência municipal. O artigo 146, inciso III, alínea $a^{17}$ já previa a competência desse instrumento legislativo para definir o fato gerador dos impostos; no caso do ISS, porém, a Constituição ratificou esse entendimento ao prever na própria norma de competência que os serviços seriam definidos em lei complementar (art. 156, inciso IV). ${ }^{18}$

Muito já se discutiu na doutrina o alcance das funções da lei complementar em matéria tributária ${ }^{19}$, mas o fato é que, como a sua própria designação já revela, cabe a essa espécie legislativa a complementação da Constituição, atuando como norma nacional, que permite uniformidade e estabilidade para as normas tributárias em nossa Federação. Evidente, no entanto, - e, por mais óbvio que isso possa parecer, é importante frisá-lo - que essas normas estão submetidas ao texto constitucional, não podendo de forma alguma contrariá-lo, como, aliás, qualquer espécie normativa do nosso ordenamento jurídico.

Dessa forma, o legislador infraconstitucional, ainda que em sede de lei complementar, deve ater-se à tarefa de elucidar e reforçar os comandos veiculados pelo constituinte, gerando estabilidade e uniformidade ao ordenamento, estando terminantemente vedado a extrapolar tal função, inovando e prescrevendo condutas diversas daquelas expressamente autorizadas pelo texto da Carta Magna. Vale dizer que esse lembrete é importante também para o intérprete, na medida em que o orienta no sentido de que o exame da legislação complementar há de ser efetuado de acordo com as regras constitucionais de competência. Ou, noutro dizer, de acordo com uma visão sistemática do ordenamento, respeitando-se os limites impostos pela própria Constituição à disciplina do ISS. ${ }^{20}$

A expressão definidos em lei complementar (art. 156, inciso IV da Constituição), consequentemente, não pode ser entendida como um "cheque em branco" concedido ao legislador nacional. De forma alguma, a Constituição autoriza o legislador infraconstitucional

${ }^{17}$ Art. 146. Cabe à lei complementar:

(...) III - estabelecer normas gerais em matéria de legislação tributária, especialmente sobre:

a) definição de tributos e de suas espécies, bem como, em relação aos impostos discriminados nesta Constituição, a dos respectivos fatos geradores, bases de cálculo e contribuintes;

${ }^{18}$ Art. 156. Compete aos Municípios instituir impostos sobre:

(...) IV serviços de qualquer natureza, não compreendidos no art. 155, I, b, definidos em lei complementar.

${ }_{19}$ A título exemplificativo: BORGES, José Souto. Lei Complementar Tributária. São Paulo: Editora da Universidade Católica, 1975; O Código Tributário e as normas gerais de Direito Tributário. In: SANTI, Eurico Marcos Diniz (Org.). Curso de Direito Tributário e Finanças Públicas - do fato à norma, da realidade ao conceito jurídico. v. 1. 1. ed. São Paulo: Saraiva, 2007; ATALIBA, Geraldo. Estudos e pareceres de direito tributário. v. III. São Paulo: Revista dos Tribunais, 1980.

${ }^{20}$ Nesse sentido: BARRETO, Aires F. ISS na Constituição e na Lei. 2. ed. São Paulo: Dialética, 2005, p. 106; CARVALHO, Paulo de Barros. Direito Tributário, Linguagem e Método. 3. ed. São Paulo: Noeses, 2009, pp. 764-765. 
a conceituar como serviço o que serviço não é. ${ }^{21}$ Isso, nas palavras de AIRES BARRETO equivaleria a dizer que a lei complementar pode, a seu talante, modificar a Constituição; que a limitação posta pela Constituição à competência municipal para só tributar atividades configuradoras de serviço, não tem a menor relevância, já que pode ser desobedecida por lei complementar. $^{22}$

Diante disso, mesmo que se reconheça o papel imprescindível da lei complementar para a instituição do ISS, em hipótese alguma, se pode reconhecer a legitimidade para que esta imponha esse imposto sobre situações que não configurem o núcleo do critério material da hipótese de incidência expressamente definido pelo constituinte, qual seja, a existência de prestação de serviço.

Desconsiderar os limites constitucionais impostos de forma rígida e, por vezes, repetitiva na Constituição, seria o mesmo que dizer que ela teria uma condicionante que, em verdade, nada condicionaria; que teria pretensos limites jurídicos que não serviriam a nenhum propósito; teria um controle que nada controlaria, como já dispôs PAULO AYRES sob outra perspectiva, mas que serve perfeitamente para o caso em tela. ${ }^{23} \mathrm{~A}$ análise de quaisquer dos (sub)itens da Lista Anexa à Lei Complementar no . 116/03, portanto, precisa partir dessa perspectiva. É o que nos propomos a fazer em seguida com relação ao subitem 25.03, relativo aos planos e convênios funerários.

\section{A INEXISTÊNCIA DE SERVIÇO TRIBUTÁVEL NA SIMPLES CONTRATAÇÃO DE PLANO OU CONVÊNIO FUNERÁRIO}

A Lista Anexa à Lei Complementar no ${ }^{\circ}$ 116/03 prevê, em seu subitem 25.03, a tributação pelo ISS sobre os planos ou convênios funerários, nos seguintes termos:

\footnotetext{
25 - Serviços funerários.

25.01 - Funerais, inclusive fornecimento de caixão, urna ou esquifes; aluguel de capela; transporte do corpo cadavérico; fornecimento de flores, coroas e outros paramentos; desembaraço de certidão de óbito; fornecimento de véu, essa e outros adornos; embalsamento, embelezamento, conservação ou restauração de cadáveres.

25.02 - Cremação de corpos e partes de corpos cadavéricos.

25.03 - Planos ou convênio funerários.
}

\footnotetext{
${ }^{21}$ Também nessa linha: CARVALHO, Paulo de Barros. Não-Incidência do ISS sobre Atividades de Franquia (Franchising), Revista de Estudos Tributários, v. 56, jul-ago/07, pp. 65-79.

${ }^{22}$ BARRETO, Aires F. ISS na Constituição e na Lei. 2. ed. São Paulo: Dialética, 2005, p. 108.

${ }^{23}$ BARRETO, Paulo Ayres. Contribuições - Regime Jurídico, Destinação e Controle. São Paulo: Noeses, 2006, p. 167.
} 
Como se percebe, o legislador diferenciou serviços funerários gerais (previstos no subitem 25.01) e serviços de cremação (previstos no subitem 25.02) de planos ou convênios funerários. Nesse ponto, vale explicitarmos que os planos ou convênios funerários são uma forma de contrato para prestação de serviços futuros, contratado em vida, para custear os gastos funerários ou de cremação quando o beneficiário vier a falecer. São contratos pagos de forma antecipada e sem data para serem cumpridos. Noutro dizer, trata-se de uma compra antecipada de um serviço que será provavelmente prestado no futuro, ainda que sem data certa.

Dissemos provável porque ainda que a morte seja certa, não é certa a existência de um corpo para a realização dos eventos fúnebres. A título exemplificativo, basta citarmos os casos de acidentes aéreos e os desaparecimentos. Ou seja, mesmo que seja provável que o serviço seja prestado em algum momento posterior, não é possível se afirmar que ele será certo. Esclarecida a natureza desse tipo de plano ou convênio, cabe analisarmos o texto legal.

Em uma primeira leitura do dispositivo citado, o legislador parece ter considerado que a contratação antecipada dos serviços funerários, que serão prestados no momento da morte do beneficiário, seria um serviço diferente daquele contratado no momento do falecimento, com prestação imediata do serviço (subitens 25.01 e 25.02). Com essa diferenciação em subitens separados, poder-se-ia entender que haveria a autorização legal para cobrar ISS no ato da contratação do plano ou convênio funerário, caracterizando esse negócio jurídico como a própria prestação de serviço.

Esse contrato em si, contudo, enquanto um contrato de provável prestação de serviços no futuro não configura desde já uma prestação de serviço. Ainda que o serviço futuro só seja prestado devido a esse negócio jurídico já firmado e pago, não se pode afirmar que desde a contratação do plano ou convênio exista serviço.

Reitera-se: a prestação de serviço não se confunde com o negócio jurídico no qual ela está inserida. A competência municipal refere-se à tributação de serviços de qualquer natureza e não de contratos prevendo a prestação de serviços ou da renda ou do lucro decorrente desses contratos. Nesse sentido, o posicionamento de AIRES BARRETO é expresso: "o ISS é devido pelo fato prestar serviço e não pelo negócio jurídico de que decorre a prestação. $O$ que revela considerar não é a causa jurídica, mas a atividade material em que consiste o serviço". ${ }^{24}$

\footnotetext{
${ }^{24}$ BARRETO, Aires F. Curso de Direito Tributário Municipal. São Paulo: Saraiva, 2009, p. 332.
} 
A única situação de fato tributável no caso dos planos ou convênios funerários é a prestação dos serviços fúnebres e de cremação, caso estes venham, de fato, a ocorrer. Portanto, o pretenso serviço tributável aqui se confunde com os serviços previstos nos subitens 25.01 e 25.02, conforme o plano firmado diga respeito a serviços fúnebres em geral ou serviços de cremação. Em outras palavras, ainda que o legislador complementar tenha indicado que entende que o próprio plano ou convênio funerário já revela uma situação tributável para fins de ISS, na medida em que o diferenciou em um subitem a parte, a verdade é que o plano em si não configura nenhuma prestação de serviço e, nesse sentido, não se coaduna com a hipótese de incidência prevista constitucionalmente para o ISS.

Nessa linha, imperioso reconhecer que a mera contratação do plano não configura serviço e não se enquadra como o fato gerador (enquanto situação necessária e suficiente para a sua ocorrência, nos termos do art. 114 do $\mathrm{CTN}^{25}$ ) para fins de tributação pelo ISS. No entanto, caso o serviço seja efetivamente prestado no futuro, nesse momento, estarão satisfeitas as condições para a incidência da norma e, portanto, haverá fato gerador passível de tributação. Até lá, o que existe é uma simples promessa de prestação de serviço, uma utilidade ou conforto no sentido de que, caso venha a falecer, a pessoa terá direito aos cotejos fúnebres acertados contratualmente. Essa promessa de utilidade, porém, não é suficiente para a tributação, uma vez que a outorga de competência refere-se a serviço e não a simples utilidade.

Além disso, parte da doutrina entende que a mera contratação do plano ou convênio funerário não se caracterizaria como uma obrigação de fazer, o que também excluiria a possibilidade de tributação pelo ISS. Para esses autores, o plano ou convênio se aproximaria da noção de contrato de seguro. JOSÉ EDUARDO SOARES DE MELO, por exemplo, é claro ao expor que "planos ou convênios funerários não constituem nenhuma obrigação de fazer, em razão do que não deveriam sujeitar-se à incidência do ISS ${ }^{\text {’26 }}$. O argumento é de que esses planos se aproximam de um plano de seguro, como planos de saúde e planos previdenciários, e que, nesses casos, a obrigação assumida pela empresa é uma obrigação de dar e não de fazer.

Também NATÁLIA DE NARDI DÁCOMO segue essa linha, afirmando que os planos ou convênios funerários têm a característica de seguro, só havendo o pagamento do valor acordado em caso de morte. E, considerando que as seguradoras estão fora da abrangência do

\footnotetext{
${ }^{25}$ Art. 114. Fato gerador da obrigação principal é a situação definida em lei como necessária e suficiente à sua ocorrência.

${ }^{26}$ MELO, José Eduardo Soares de. ISS - Aspectos Teóricos e Práticos. 4. ed. São Paulo: Dialética, 2005, p. 125.
} 
campo do ISS, pois se trata de operação financeira e não relação de prestação de serviço, a autora também conclui pela impossibilidade de cobrança sobre esse tipo de plano. ${ }^{27}$

É preciso, contudo, diferenciar os casos em que o plano ou convênio funerário se caracteriza como uma verdadeira relação de seguro, em que a seguradora se obriga a pagar uma quantia pré-estabelecida, caso ocorra o sinistro (morte $)^{28}$; daqueles casos em que há verdadeiro pagamento antecipado do serviço que será prestado diretamente pela contratada, quando o contratante vier a falecer. Nessa segunda hipótese, a empresa não se obriga a um pagamento em dinheiro, mas sim a própria prestação direta do serviço, com a única diferença de que o beneficiário o pagou de forma antecipada, ainda em vida. Apenas na primeira situação o plano ou convênio se aproxima da noção de seguro, sendo que na segunda ele nada mais é do que um pagamento antecipado por prováveis serviços futuros.

Esse tipo de plano ou convênio funerário, mesmo que se aproxime da figura de plano de seguro, tem características próprias, que o tornam bastante singular. Trata-se de uma promessa de obrigação de fazer com data incerta e grande probabilidade de ser realizada, mas sem certeza. Evidente, portanto, as dificuldades de caracterizá-lo. O que importa é que certamente a simples contratação dessa "promessa de serviço" não serve como figura apta a caracterizar o critério material da hipótese de incidência do ISS, uma vez que não se caracteriza, por si só, como uma prestação de serviço. Haverá prestação de serviço, porém, quando o contratante vier a falecer e a empresa efetivamente prestar de forma direta os serviços relativos aos cotejos fúnebres, havendo aí a situação necessária e suficiente para o surgimento do fato gerador do ISS e sendo cabível, então, a cobrança do ISS.

Com isso, percebemos como a definição do núcleo do critério material é relevante para explicitar todos os demais aspectos do fato gerador. Aceitando-se que o critério material do ISS não pode ser outro senão a própria prestação de serviço, torna-se possível a verificação dos demais critérios da hipótese de incidência, especialmente os critérios temporal e local. $\mathrm{O}$ aspecto temporal, por exemplo, deverá ser necessariamente o momento da prestação de serviços. No caso dos planos ou convênios funerários essa questão cresce de importância, uma vez que na data da contratação do plano ou convênio funerário e mesmo na data do seu pagamento ainda não é possível afirmar quando o serviço será efetivamente prestado, ou seja, quando irá ocorrer o fato gerador.

\footnotetext{
${ }^{27}$ DÁCOMO, Natalia de Nárdi. Hipótese de Incidência do ISS. São Paulo: Noeses, 2007, p. 263.

${ }^{28}$ Nesse sentido, o Código Civil: Art. 757. Pelo contrato de seguro, o segurador se obriga, mediante o pagamento do prêmio, a garantir interesse legítimo do segurado, relativo a pessoa ou a coisa, contra riscos predeterminados.
} 
Questão muito discutida na doutrina e na jurisprudência, e que pode servir também para o presente caso, diz respeito à tributação dos serviços de diversão pública. Muitos Municípios pretenderam cobrar o ISS quando da chancela dos ingressos. Esse posicionamento, no entanto, foi repudiado na doutrina. AIRES BARRETO, por todos, foi enfático ao repudiar a prática, afirmando que o fato "prestação de serviço", no caso de diversão pública, embora tenha início com o efetivo exercício, pelos usuários, do direito de participar, ou de assistir aos espetáculos, só se conclui e se aperfeiçoa no momento em que, adentrando o recinto, o assistente (ou participante) exerce esse direito. O fato gerador não é consubstanciado no direito de assistir, ou no de participar do início do espetáculo, daí por que só se desencadeia com o término do próprio espetáculo. Antes disso, qualquer que seja o momento antecedente não se tem nenhum fato gerador porque prestação de serviços não há. ${ }^{29}$

Esse mesmo entendimento, portanto, é plenamente aplicável para o caso dos planos ou convênios funerários, já que também aqui o direito de ser enterrado ou cremado conforme acertado de forma prévia no contrato não se consubstancia como prestação de serviço, que só ocorrerá quando da efetiva prestação dos serviços fúnebres ou de cremação.

Em sentido contrário, há quem defenda que a existência de capacidade contributiva já seria suficiente para justificar a tributação antecipada dos serviços nesses casos. ${ }^{30}$ Não podemos concordar com esse posicionamento, especialmente porque a nossa Constituição não autorizou a incidência tributária a partir da mera existência de capacidade contributiva, mas sim com base em uma rígida determinação de competências materiais que precisam ser respeitadas. Ora, se os entes federativos estivessem autorizados a cobrar tributos pela simples existência da capacidade contributiva, instalado estaria o caos e todo o sistema exaustivo previsto na Constituição perderia seu sentido.

Além disso, ainda que isso não fosse motivo suficiente para a tributação pelo ISS, imperioso dizer que esses valores recebidos pela empresa não ficam descobertos da tributação, já que são incluídos na base de cálculo dos tributos sobre a renda, a receita e o lucro. Como, no entanto, o ISS não tem como materialidade nenhuma dessas grandezas, e sim

\footnotetext{
${ }^{29}$ BARRETO, Aires F. Curso de Direito Tributário Municipal. São Paulo: Saraiva, 2009, p. 335.

${ }^{30}$ Esse posicionamento pode ser verificado na própria jurisprudência do STJ, que reconheceu a possibilidade de tributação pelo ISS incidente sobre os serviços de diversão pública já no momento da venda dos ingressos: TRIBUTÁRIO - ISS - DIVERSÕES PÚBLICAS - FATO GERADOR - ARTIGOS 114 E 116 DO CTN.1. O fato gerador do ISS reside na efetiva prestação de serviço, definido em lei complementar, constante da Lista de Serviços anexa ao Decreto-Lei 406/68.2. Em se tratando de ISS incidente sobre diversões públicas, o fato imponível se configura no momento da venda do ingresso ao consumidor, pelo que ilegítima a antecipação do recolhimento, quando da chancela prévia dos bilhetes pelo município. (REsp 159.861/SP, Rel. Ministro HUMBERTO GOMES DE BARROS, PRIMEIRA TURMA, julgado em 13/10/1998, DJ 14/12/1998, p. 109.)
} 
os valores recebidos a título de prestação de serviços, evidente que enquanto esses não forem efetivamente prestados, esse imposto não poderá incidir.

No que toca ao aspecto local da hipótese de incidência, importante perceber que a própria Lei Complementar $n^{\circ}$. 116/03 foi coerente com o critério material ao prever que se considera estabelecimento prestador o local onde o contribuinte desenvolva a atividade de prestar serviços. ${ }^{31}$ Nem faria sentido entender o contrário, uma vez que a competência municipal seja para tributar a prestação de serviço, evidente que o único ente competente para fazê-lo é aquele no qual o serviço for efetivamente prestado.

Também aqui se demonstra porque a tributação não poderia incidir quando da simples contratação do plano ou convênio funerário, já que, nesse momento, ainda não é possível saber qual o Município competente para a cobrança do tributo. Imaginemos a situação de uma empresa que trabalha no ramo e atua com estabelecimentos permanentes em mais de um Município: não é incoerente imaginar que uma pessoa possa contratar o serviço na cidade em que reside (Município A), mas as cerimônias fúnebres ocorram em outro Município (B), por sua decisão ou até da própria família. Dessa forma, mesmo que o serviço tenha sido contratado no Município A, o Município competente para a tributação será o Município B e isso será verificável tão-somente quando da própria morte.

Em suma, constatado que o aspecto material da hipótese de incidência só ocorre quando da efetiva prestação dos serviços fúnebres nos planos ou convênios funerários, não há dúvida de que o ISS só poderá ser cobrado no momento da prestação do serviço e no local em que isso efetivamente ocorrer. Dessa forma, independente da indicação do legislador complementar, que entendeu por bem diferenciar os planos e convênios da efetiva prestação dos serviços funerários e de cremação, a verdade é que não há um serviço diferente nesse caso, mas sim uma simples promessa de prestação provável de serviços.

As dificuldades vinculadas à aferição da base de cálculo, uma vez que a ocorrência do fato gerador ocorre em momento posterior daquele em que o serviço foi efetivamente pago (data da contratação), gerando questionamentos e dificuldades quanto à necessidade de correção do preço pago, não justificam o desrespeito à Constituição. Noutro dizer, não pode o legislador, em nome da simplificação e da praticidade, cobrar tributo sobre mera utilidade ou serviço potencial, uma vez que detém autorização tão-somente para a tributação da prestação

\footnotetext{
${ }^{31}$ Art. $4^{\circ}$ Considera-se estabelecimento prestador o local onde o contribuinte desenvolva a atividade de prestar serviços, de modo permanente ou temporário, e que configure unidade econômica ou profissional, sendo irrelevantes para caracterizá-lo as denominações de sede, filial, agência, posto de atendimento, sucursal, escritório de representação ou contato ou quaisquer outras que venham a ser utilizadas.
} 
efetiva de serviços. Noutro dizer, a simplicidade e a eficiência tributária não servem como fundamento para que se ignorem as diretrizes fundamentais do Texto Constitucional, sempre em prejuízo do contribuinte. ${ }^{32}$

Diante disso, o subitem 25.03 não cria uma nova hipótese de incidência e, na verdade, se mostra inútil, considerando que os possíveis serviços prestados nesse caso serão aqueles previstos nos subitens 25.01 e 25.02. A tentativa do legislador de tributação imediata desses planos ou convênios funerários, portanto, não se coaduna com as diretrizes impostas pela Constituição.

\section{ANÁLISE CRÍTICA DA JURISPRUDÊNCIA DO TRIBUNAL DE JUSTIÇA DE SÃO PAULO E DO SUPERIOR TRIBUNAL DE JUSTIÇA}

O presente tema tem crescido de importância na medida em que não apenas mais empresas passaram a atuar nesse mercado, como também os Municípios passaram a autuá-las com o objetivo fazer incidir o ISS já na contratação desse tipo de plano ou convênio funerário. Em São Paulo, por exemplo, essa matéria foi recentemente debatida pelo Tribunal de Justiça em um caso envolvendo empresa que vendia planos funerários e o Município de Jaú, que pretendia tributá-la já no momento da contratação desses negócios jurídicos.

O Município obteve decisão favorável em primeira instância, mas a sentença foi reformada pelo Tribunal de Justiça de São Paulo, que reconheceu que a exigibilidade do imposto depende da efetiva prestação do serviço e não apenas do pagamento adiantado das parcelas. Eis a ementa desse julgamento:

ISSQN - PLANOS OU CONVÊNIOS FUNERÁRIOS - LEGALIDADE -EFETIVA PRESTAÇÃO DE SERVIÇOS - NECESSIDADE Mesmo havendo previsão de incidência do ISSQN sobre planos ou convênios funerários (item 25.03 da lista anexa à Lei Complementar n" 116/03), a exigibilidade do imposto deve ser compreendida à luz da determinação constitucional de que o seu fato gerador é a prestação de serviços (art. 156, III), de forma que, no caso concreto, para que seja possível a cobrança, é necessária a efetiva prestação do serviço e não apenas o pagamento adiantado das parcelas. RECURSO PROVIDO. ${ }^{33}$

\footnotetext{
${ }^{32}$ BARRETO, Paulo Ayres. Tributação sobre o Consumo: Simplicidade e Justiça Tributária. In: SANTI, Eurico Marcos Diniz de (Org.). Tributação e Desenvolvimento: Homenagem ao Professor Aires Barreto. São Paulo: Quartier Latin, 2011, p. 532.

33 Apelação com revisão n 990.10.104312-2, 18a Câmara de Direito Público do Tribunal de Justiça de São Paulo, Relator Carlos Alberto Giarusso Lopes Santos, DJ 11/08/2011.
} 
Em seu voto, o Desembargador Relator Carlos Alberto Santos demonstra a lógica seguida na decisão, no sentido de que a mera existência do plano ou convênio funerário, por si só, não autoriza a cobrança do ISS, sendo necessária a efetiva prestação dos serviços funerários para tornar o tributo exigível. Observa ainda que o plano ou convênio funerário é negócio jurídico com eficácia condicionada à ocorrência da morte, oportunidade em que ocorre a prestação dos serviços, os quais já haviam sido remunerados de maneira parcelada pelo adquirente, desde o momento da adesão ao plano. Nessa linha, os julgadores repudiaram a cobrança do ISS desde a contratação do plano.

Ainda que a questão dos planos ou convênios funerários seja bastante recente, e, portanto, ainda não tenha uma jurisprudência consolidada, outros temas correlatos já foram analisados pelo Tribunal de Justiça de São Paulo e podem auxiliar na solução desse caso. Questão análoga a essa se refere à cobrança do ISS sobre contratos de assistência técnica, em que o contratante se obriga a possível prestação de serviços de reparo em equipamentos, em troca do pagamento antecipado de determinada quantia.

Ocorre que também nesse caso a prestação do serviço será eventual e futura, não se confundindo com a simples contratação no negócio jurídico. Analisando o tema, o Tribunal de Justiça de São Paulo mais uma vez se mostrou atento à Constituição, afastando a possibilidade de incidência do ISS no momento da simples contratação:

ISS - Contrato de manutenção - Fornecimento de peças sobressalentes e mão-deobra para maquinas e aparelhos empregados no lar- Pagamento prévio ajustado, sem ônus adicional na eventual e futura prestação da assistência técnica - Incidência sobre a real prestação de serviços, e não sobre o contrato - Tributo que onera a prestação de serviços, e não eventual lucro - Fato gerador não apurado - Embargos à execução fiscal Julgados procedentes (...) 3. A controvérsia reside em saber se incide ou não e em que momento o imposto sobre serviços em decorrência do contrato de manutenção celebrado entre a apelada e seus clientes, por meio do qual o adquirente do aparelho eletrodoméstico, mediante prévio pagamento ajustado no instrumento e sem ônus adicional, passa a ter direito ao fornecimento de peças sobressalentes e mão-de-obra (conserto) por determinado período, com garantia de bom funcionamento do produto. Efetivamente, a razão está com a r. sentença e a apelada, entendendo que o imposto é devido sobre a efetiva prestação do serviço, com a solicitação feita pelo cliente, momento em que ocorre o fato gerador, e não sobre o contrato ou negócio jurídico de manutenção estabelecido. Ao contrário do pretendido pela Fazenda apelante não basta celebrar o contrato para eventual e futura realização do serviço nem era ônus da apelada provar que não houve a efetiva prestação da atividade. Se o serviço não foi prestado e, segundo os contratos (fls. 40/42), poderia até ocorrer a hipótese de não se concretizar a prestação, caso o bem não necessitasse de reparos, seja por aplicação de mão-de-obra, seja com substituição de peças, no período da garantia, a indigitada liqüidez e certeza das certidões de divida ativa, uma vez impugnadas, reclamavam um mínimo de indícios da real prestação dos serviços como, por exemplo, relação de notas fiscais, de ordens de execução do serviço etc., que as cópias dos autos de infração não trazem (fls. 
37/42 e 50/52), nem a Fazenda interessada cuidou de providenciar, fiando-se apenas em ilimitada mas, no caso, meramente teórica. ${ }^{34}$

Como se percebe, também aqui a fundamentação parte do respeito ao critério material da hipótese de incidência do ISS, preservando a rígida discriminação constitucional das competências, que, no caso dos Municípios, autoriza a incidência de ISS somente quando da efetiva prestação de serviços.

No Superior Tribunal de Justiça, decisões em casos similares envolvendo discussões sobre o ISS também podem servir de parâmetro para o caso dos planos ou convênios funerários, ainda não discutido nesse Tribunal. Por um lado, sobre o tema do ISS incidente sobre diversões públicas, a jurisprudência do STJ se mostrou mais vacilante, porque, ainda que tenha repudiado a cobrança do ISS quando da chancela dos ingressos, aceitou que esse incida no momento da venda dos ingressos. ${ }^{35}$

Por outro lado, decisões sobre outros serviços corroboram a impossibilidade de cobrança antecipada do ISS, quando ainda não há efetiva prestação de serviço. Analisando a incidência do ISS sobre serviços de assistência médica prestados mediante convênio, por exemplo, o STJ foi enfático ao afirmar "que o fato gerador do ISS, seu pressuposto de fato, dá-se no momento da prestação do serviço, e não quando do pagamento do serviço realizado".36

A questão relativa ao aspecto local da hipótese de incidência também já se encontra pacificada no Tribunal, tendo sido julgada na sistemática dos recursos repetitivos em 2011. Nesse julgado, em que se discutia sobre os serviços de manutenção e aluguel de maquinaria, o STJ pacificou seu entendimento no sentido de que "o ISS deve ser recolhido no local da efetiva prestação de serviços, pois é nesse local que se verifica o fato gerador (nos termos do art.12, letra "b", do DL n. 406/1968 e art. 3", da LC n. 116/2003)". ${ }^{37}$

\footnotetext{
${ }^{34}$ Apelação com Revisão 0063110-47.1998.8.26.0000, $1^{\text {a }}$ Câmara (Extinto $1^{\circ}$ TAC), Relator Correia Lima, DJ 24/09/2001.

${ }^{35}$ REsp 159.861/SP, Rel. Ministro HUMBERTO GOMES DE BARROS, PRIMEIRA TURMA, julgado em 13/10/1998, DJ 14/12/1998, p. 109.

${ }^{36}$ Voto do Ministro Relator Teori Zavascki no seguinte julgamento: TRIBUTÁRIO. ISS. PRESTAÇÃO DE SERVIÇOS MÉDICOS MEDIANTE CONVÊNIOS. FATO GERADOR. MOMENTO DA OCORRENNCIA. PECULIARIDADES. APRESENTAÇÃO E APROVAÇÃO DAS CONTAS PELO PRESTADOR À EMPRESA ADMINISTRADORA DO PLANO DE SAÚDE. RECURSO IMPROVIDO. (REsp 887.385/RJ, Rel. Ministro TEORI ALBINO ZAVASCKI, PRIMEIRA TURMA, julgado em 14/12/2010, DJe 17/12/2010.) ${ }^{37}$ PROCESSUAL CIVIL E TRIBUTÁRIO. ISS. COMPETÊNCIA. LOCAL DA PRESTAÇÃO DO SERVIÇO. QUESTÃO PACIFICADA PELA PRIMEIRA SEÇÃO. RESP 1.117.121/SP. APLICAÇÃ̃O DO ART. 543-C DO CPC. 1. A Primeira Seção desta Corte, consolidou o entendimento no sentido de que o ISS deve ser recolhido no local da efetiva prestação de serviços, pois é nesse local que se verifica o fato gerador (nos termos do art.12, letra "b", do DL n. 406/1968 e art. $3^{\circ}$, da LC n. 116/2003). 2. In casu, a empresa encontra-se sediada
} 
Dessa forma, ainda que pendente de análise definitiva pelo STJ, órgão competente para decidir acerca da interpretação da legislação infraconstitucional, as decisões citadas indicam um caminho no sentido do reconhecimento pela jurisprudência da impossibilidade de tributação imediata pelo ISS na contratação de planos ou convênios funerários, na medida em que esse entendimento se mostre o único condizente com o Texto Constitucional.

\section{CONSIDERAÇÕES FINAIS}

Considerando que a Constituição brasileira tem como uma de suas principais características a discriminação rígida das competências tributárias, tendo por vezes delimitado o próprio critério material da hipótese de incidência, não há como se fugir da análise constitucional de qualquer exação tributária. Esse desenho constitucional nada mais fez do que impor limites rígidos ao legislador infraconstitucional, estando ele necessariamente vinculado ao espaço de atuação delimitado pelas normas do Texto Constitucional.

O ISS não foge a essa regra, tendo a própria Constituição informado que a sua cobrança só estaria autorizada na existência de um serviço, enquanto uma obrigação de fazer em que alguém se obriga a realizar um esforço humano em benefício de outrem. Delimitado o núcleo do critério material da hipótese de incidência, evidente que a remissão ao legislador complementar, prevista no próprio texto da Constituição, não significa um "cheque em branco" para que este defina qualquer atividade como serviço. O legislador tem competência para definir quais são os serviços tributáveis, mas não a tem para definir como serviço aquilo que serviço não o é.

Firmadas essas premissas, partimos para a análise do subitem 25.03 da Lista Anexa à Lei Complementar $\mathrm{n}^{\circ}$. 116, esperando termos demonstrado que, a par da tentativa do legislador complementar de diferenciar os planos ou convênios funerários dos demais serviços funerários gerais e de cremação, a simples contratação para a prestação provável de serviços futuros não se consubstancia como situação necessária e suficiente para o surgimento do fato gerador do ISS.

Primeiro, porque a prestação de serviços não se confunde com o negócio jurídico ao qual ela está vinculada. Ainda que a existência de uma relação jurídica onerosa seja um aspecto fundamental para a incidência do imposto, esta não se confunde com o núcleo do 
critério material, que é a própria prestação dos serviços. Os Municípios não foram autorizados a tributar negócios jurídicos envolvendo a prestação de serviços, mas sim a própria prestação, situações jurídicas que não se confundem. Também não foram autorizados a cobrar por serviços meramente potenciais. Em resumo, a utilidade e o benefício não se confundem com a existência de prestação de serviço.

Segundo, porque a mera existência de capacidade contributiva não serve como justificativa para a antecipação da cobrança. Por um lado, se os entes federados estivessem autorizados a instituir tributos sobre a simples existência de capacidade econômica, toda a rígida discriminação de competências prevista na Constituição perderia seu sentido. Por outro lado, vale dizer que esses valores integrarão a receita, a renda e o lucro das empresas, mas essas materialidades não fazem parte da outorga de competência dos Municípios.

Terceiro, enquanto não efetivamente prestado o serviço funerário contratado, não é possível apontar qual o Município competente para o recolhimento do tributo. Isso porque é possível que a empresa atue em mais de uma localidade, e que o local aonde o contrato tenha sido firmado não seja o mesmo local em que o serviço será efetivamente prestado, podendo a empresa possuir estabelecimentos permanentes em ambos.

Não nos resta dúvida, portanto, de que os planos ou convênios funerários, previstos no subitem 25.03 da Lista Anexa à Lei Complementar nº 116/03, à luz da Constituição e das normas gerais do Código Tributário Nacional, só se consubstanciam como fatos geradores do ISS quando da efetiva prestação dos serviços funerários contratados. Até lá, existe mera promessa de prestação de serviços, utilidade essa que não é alcançada pela outorga de competência constitucional aos Municípios e, exatamente por isso, não pode ser alcançada pelo ISS.

\section{REFERÊNCIAS}

ALEXY, Robert. Juristiche Interpretation. In: Recht, Vernunft, Diskurs. Frankfurt am Main: Suhrkamp, 1995.

ATALIBA, Geraldo. Estudos e pareceres de direito tributário. v. III. São Paulo: Revista dos Tribunais, 1980. 
ÁVILA, Humberto. Conceito de renda e compensação de prejuízos fiscais. São Paulo: Malheiros, 2011.

Imposto sobre a Prestação de Serviços de Qualquer Natureza. ISS. Normas constitucionais aplicáveis. Precedentes do Supremo Tribunal Federal. Hipótese de incidência, base de cálculo e local da prestação. Leasing financeiro: análise da incidência. Revista Dialética de Direito Tributário, v. 182, São Paulo, nov./2010, pp. 133-144.

BARRETO, Aires Fernandino. Curso de Direito Tributário Municipal. São Paulo: Saraiva, 2009.

. ISS na Constituição e na Lei. 2. ed. São Paulo: Dialética, 2005.

BARRETO, Paulo Ayres. Tributação sobre o Consumo: Simplicidade e Justiça Tributária. In: SANTI, Eurico Marcos Diniz de (Org.). Tributação e Desenvolvimento: Homenagem ao Professor Aires Barreto. São Paulo: Quartier Latin, 2011, pp. 529-545.

. Elisão Tributária: Limites Normativos. São Paulo, USP, 2008.

. Contribuições - Regime Jurídico, Destinação e Controle. São Paulo: Noeses, 2006.

BORGES, José Souto. Lei Complementar Tributária. São Paulo: Editora da Universidade Católica, 1975.

CARVALHO, Paulo de Barros. Curso de Direito Tributário. 23. ed. São Paulo: Saraiva, 2011.

Direito Tributário, Linguagem e Método. 3. ed. São Paulo: Noeses, 2009.

- Não-Incidência do ISS sobre Atividades de Franquia (Franchising), Revista de Estudos Tributários, v. 56, jul-ago/07, pp. 65-79.

DÁCOMO, Natalia de Nárdi. Hipótese de Incidência do ISS. São Paulo: Noeses, 2007.

DERZI, Misabel de Abreu Machado. Direito Tributário, Direito Penal e Tipo. São Paulo, Revista dos Tribunais, 1988. 
MELO, José Eduardo Soares de. ISS - Aspectos Teóricos e Práticos. 4. ed. São Paulo: Dialética, 2005.

MOSQUERA, Roberto Quiroga. Os Impostos sobre Operações de Crédito, Câmbio, Seguro ou Relativos a Títulos ou Valores Mobiliários - Conceitos Fundamentais. In: SANTI, Eurico Marcos Diniz de; ZILVETI, Fernando Aurélio; MOSQUERA, Roberto Quiroga (Orgs.). Tributação Internacional e dos Mercados Financeiro e de Capitais. São Paulo: Quartier Latin, 2005, pp. 101-175.

Renda e proventos de qualquer natureza - o imposto e o conceito constitucional. São Paulo: Dialética, 1996.

SANTI, Eurico Marcos Diniz de; BARRETO, Paulo Ayres. Contribuições para Previdência Privada - Dedutibilidade em face do Imposto sobre a Renda - Força da EC 20/98 Aplicabilidade da Lei 9.532/97 no Tempo. Revista Dialética de Direito Tributário, vol. 93, junho/03, pp. 124-133.

O Código Tributário e as normas gerais de Direito Tributário. In: SANTI, Eurico Marcos Diniz (Org.). Curso de Direito Tributário e Finanças Públicas - do fato à norma, da realidade ao conceito jurídico. v. 1. 1. ed. São Paulo: Saraiva, 2007, pp. 322-329.

SCHOUERI, Luís Eduardo. Direito Tributário. São Paulo: Saraiva, 2011. 2005.

Normas Tributárias Indutoras e Intervenção Econômica. Rio de Janeiro: Forense,

Discriminação de Competências e Competência Residual. In: SCHOUERI, Luís Eduardo; ZILVETI, Fernando Aurélio (Orgs.). Direito Tributário: Estudos em Homenagem a Brandão Machado. São Paulo, 1998, pp. 82-115.

TORRES, Heleno. A Hipótese do ICMS sobre Operações Mercantis na Constituição e a Solução de Conflitos Normativos. In: SCHOUERI, Luís Eduardo (Org.). Direito Tributário Homenagem a Paulo de Barros Carvalho. São Paulo: Quartier Latin, 2008, pp. 321-342.

Submissão: 05/09/2013

Aceito para Publicação: 21/11/2013 